\title{
Millennium Development Goals: A Concern Over Sub-National Variations
}

Stephanié Rossouw, AUT University, New Zealand

Don J. Webber, AUT University, New Zealand

\begin{abstract}
Millennium development goals (MDGs) were agreed upon by 192 countries in the year 2000 and are due to be achieved by 2015. This paper highlights that MDGs deal with national averages and their achievement may hide sub-national variation. Sub-national variation in the ability to achieve development goals should be expected because government spending would achieve such goals faster if it were targeted at areas where the required improvements are smaller, as is often the case in city-regions. Rural and dispersed populations may gain little from MDGs, at least in the short run. Data analysis of South African Magisterial Districts highlights this issue.
\end{abstract}

Keywords: Millennium Development Goals; Sub-national variation; City-region; Urban bias

\section{INTRODUCTION}

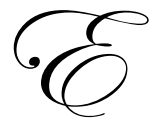

ight Millennium Development Goals (MDGs) were agreed upon at the United Nations Millennium Summit in 2000 by 192 countries in order to improve the living conditions of the world's population. These MDGs are to:

1. Reduce extreme poverty and hunger by half relative to 1990

2. Achieve universal primary education

3. Promote gender equality and empowerment of women

4. $\quad$ Reduce child mortality by two-thirds relative to 1990

5. Improve maternal health, including reducing maternal mortality by three-quarters relative to 1990

6. $\quad$ Prevent the spread of HIV/AIDS, malaria, and other diseases

7. Ensure environmental sustainability

8. Develop a global partnership for development

MDGs were meant as a major motivational contrivance to increase development efforts within and on behalf of poor countries. They can be seen as a fundamental promotion of human well-being from a multidimensional perspective and the principles enfolded in these goals share the concept of human well-being underlying the human development index (Chakravarty and Majumder, 2008).

Although the MDGs originated in the United Nations, country driven and nationally owned efforts are necessary for their achievement. Given that the goals are ambitious, reflecting urgent need for fast progress on development, every poor country has to prepare a national strategy that addresses these issues. They need to assess whether and how the goals can be achieved within the target period and may have to redefine policy priorities; every national development strategy should formulate national policies to attain these goals. Identification of new actions and resources may be necessary to reach the MDGs but this could also lead to attention being drawn away from certain areas or regions within a country "for the greater good" (Chakravarty and Majumder, 2008).

In this paper we highlight the disparities in a number of development measures that exist at the sub-national level; our data corresponds to South Africa. Since the MDGs are measured as national averages, and as governments do not want to be seen as failing to achieve these MDGs, allocations of resources could target those sub-national areas where the achievement of the MDGs would be relatively less challenging. This MDG-orientated allocation of 
resources may be at a cost to other sub-national areas that are much less likely to achieve the MDGs and are more in need of government, welfare-associated, resources.

\section{PROGRESS ON MDGS}

Since the MDGs were set, the performance across countries has been very mixed. Many parts of the world are making very good progress. Improvements throughout East and South Asia, home to more than half the world's population, have been especially remarkable. However, there are huge disparities between countries. Sub-Sahara Africa is in insidious crisis, with rising extreme poverty, shockingly high child and maternal mortality, and a trajectory that has many of the countries failing to meet most of the MDGs.

According to the African Economic Outlook (AEO) (2009), the geography of poverty in Africa (including South Africa) has remained unchanged and remains endemic in all regions of the continent except North Africa. In terms of labour productivity there has been some positive growth since 1991 in all sub-regions except East Africa. Although most of Africa has experienced recent positive economic growth, it has been characterised by being 'jobless' growth, as the employment-to-population ratio has remained virtually unchanged since 1991. All indications are that Africa is unlikely to reduce the number of children under 5 years of age who are underweight by 2015, as progress towards this target has been severely hampered by increases in food prices that began in late 2007. The under-5 mortality rate target is unlikely to be met as Southern Africa is plagued by an extremely high HIV prevalence rate (South Africa were $3^{\text {rd }}$ worst with a rate of 17.8 per cent) (Global report: UNAIDS report on global aids epidemic, 2010). Central Africa has a very high prevalence of malaria and political conflict is rife in many regions. Although it seems like Africa is making progress in reducing the prevalence rate of HIV/AIDS, seven Southern African countries (South Africa, Botswana, Lesotho, Namibia, Swaziland, Zambia and Zimbabwe) still have a prevalence rate in excess of 13 per cent (Global report: UNAIDS report on global aids epidemic, 2010).

The achievement of the MDGs can be hampered by development and vulnerability differences within a country. However within-country vulnerability differences can force a change in policy, which can then steer a country towards the achievement of the MDGs. For instance, an assessment of the Philippine's efforts towards achieving the MDGs was made in 2002, which noted regional disparities as one of the main challenges to overcome and suggested possible "spatial factors driving performance, such as geography and location-specific socio-political dynamics" (Collas-Monsod et al., 2004, p.121). National policies will have to be redirected towards improving the worst performing regions or else she will have a very low likelihood of achieving four of the MDGs (Collas-Monsod et al., 2004). ${ }^{1}$

Another example is the middle-income country of Mexico, which has distinct ethnic, social and regional groups. Her government uses self-defined poverty lines for food, skills and patrimonial poverty. Fuentes and Montes (2004) document many sub-regional asymmetries in Mexico and a conflicting picture emerges when comparison is made across urban and rural areas. For instance, while all poverty measures decreased in urban areas - the most significant decreases were for food poverty - the same poverty measures increased in rural areas. Patterns of territorial polarisation remain despite recent redistribution and decentralising policies. Population density is extremely high in large cities and exceptionally low in thousands of dispersed small villages, many of which are difficult to reach by regular transport modes. The percentage of children aged 5 years and under with low weight was 12.3 in rural areas and 5.7 in urban areas. Population aged 20 years and older with primary schooling is highly skewed with 68.1 per cent of them residing in urban areas compared to 31.9 per cent in rural areas. In terms of access to public infrastructure and services there exists a 20 percentage gap between rural and urban areas with access to portable water and a 70 percentage gap in sanitation services with only 9.02 per cent access in rural areas contrasting the 79.57 per cent access in urban areas. In order to eliminate sub-national disparities and meet the MDGs, Mexico has focused on various programs (e.g. Programa de Educación, Salud y Alimentación) to improve the health and educational attainments of the extreme poor, the indigenous and other vulnerable groups by providing

1 These four MDGs are: (i) halving the percentage of people living in extreme poverty; (ii) halving the percentage of population below minimum level of dietary consumption and halving the proportion of underweight under-5s; (iii) providing universal access to and completion of (to 80 per cent) primary education; and (iv) reducing maternal mortality rate by threequarters. 
economic incentives. This implies a clear geographical concern with more focus on Southern than Northern states within Mexico (Fuentes and Montes, 2004).

\section{THE SPATIAL LITERATURE}

The origins of development and vulnerability transcend the geographical, economic and political. Primary concerns associated with negative events are their impacts on productivity growth, development potential and the extent to which they alter development and vulnerability (Guillaumont, 2004). ${ }^{2}$ Recent additions to the development and vulnerability literature include Bocquier et al. (2010) who examined employment and earnings in West Africa and Calvo (2008) who finds the extent of development and vulnerability between urban and rural areas in Peru between 1998 and 2002 holds throughout the period.

Turvey (2007) advocates the need for place development and vulnerability indices and argued that without a geographical component in the measurement of development and vulnerability, the construction of development and vulnerability profiles might be useless for framing development policy and evaluating developing countries. ${ }^{3}$ Although the main spatial scale of analysis has been at the country-level there are a growing number of articles that examine development and vulnerability at the sub-national level. For instance, Bird and Prowse (2008) investigated the vulnerability of households in Zimbabwe and found that if official donors did not intervene then the poor and very poor were likely to be driven into long-term chronic poverty and such chronic poverty would be extremely difficult if not impossible to reverse. Gaiha and Imai (2008) also argued that idiosyncratic shocks (e.g. unemployment or illness) were primarily the cause of Indian rural households' vulnerability although poverty and aggregate risks (weather and crops) were also very crucial contributory factors; the last of which is clearly a geographical issue. ${ }^{4}$

Not a lot of attention has been given to the development and vulnerability of regions within a country. Hulme et al. (2001) linked poverty to the development and vulnerability of specific regions and Kanbur and Venables (2005) showed that not only is spatial inequality between regions on the increase but that it will ultimately cause an overall increase in the inequality of specific countries. Ivaschenko and Mete (2008) presented strong evidence of geographic poverty mobility traps and argue that higher levels of poverty in a region appear to reduce radically the chance of a household emerging out of poverty, and that living in a region with an overall slow economic growth weakens the odds of exiting poverty and increases the risk of slipping into poverty.

\section{SOUTH AFRICA'S PROGRESS ON THE MDGS}

South Africa is classified as a middle-income country, with a GDP per capita of approximately US\$ 5750, an overall GDP of US\$ 211.2 billion and an estimated population of over 49 million. Her economic growth rate averaged about 3 per cent during the decade after the first democratic elections which was seen as a triumph in contrast to the below average growth of 1 per cent for the preceding decade. In 2005, the growth rate reached 5 per cent and all expectations indicated this strong performance should continue. South Africa experienced exceptionally high inflows of foreign capital and foreign direct investment after 2003 which assisted in speeding up the process of employment creation; for instance, during the year ending 2005, approximately 540,000 jobs were created. Nevertheless although there has been a considerable drive for further job creation and poverty reduction in South Africa unemployment remains severe.

The Accelerated and Shared Growth Initiative for South Africa (AsgiSA) was formally launched in 2006 to help the South African Government halve poverty and unemployment by 2015. It was the conclusion of the AsgiSA

2 For a more in-depth discussion on the empirical and conceptual viewpoints of economic vulnerability, see Briguglio (1995, 2003) and Atkins et al. (2000). Guillaumont (2009) suspects that there has been an upsurge in interest concerning macro vulnerability because of the unsustainability of growth episodes and contemporaneous increase in poverty rates in Africa, the Asian crisis' unveiling of emerging markets' vulnerability and the debate surrounding the construction of an appropriate vulnerability measure that can be applied for specific country groups.

3 For further studies on country specific vulnerability see for example, Birkmann (2007), Easter (1998), Mansuri and Healy (2001), Marchante and Ortega (2006) and McGillivray et al. (2008).

4 Other household level vulnerability studies include Chaudhuri et al. (2002) and Kühl (2003). 
committee that in order for South Africa to achieve its social objectives it had to keep on growing at a rate of 5 per cent per annum until 2015, and while South Africa had a very strong and focused central government one of the major binding constraints for the achievement of this goal is the reduction of deficiencies in state organisations, capacity and leadership. AsgiSA launched Project Consolidate which was designed to address the skills problems of local government and service delivery. Skills interventions include the deployment of experienced professionals and managers to local governments to improve project development implementation and maintenance capabilities. In 2010, the New Economic Growth Path was introduced with its focal point being the creation of five million jobs by 2020. This target is said to be achievable by focusing on two key variables: the rate of economic growth and the employment intensity of that growth.

In 2008, the OECD's economic assessment $(2008$, p.1) stated that South Africa is seen as a ".....stable, modern state, (and) in many ways (is) a model for the rest of the African continent" but "there have also been notable weaknesses in (its) economic record to date, especially as regards to unemployment, inequality and poverty...HIV/AIDS and crime". This report views South Africa not as a vulnerable state in the traditional sense but it does recognise the role its strong institutions played in bringing about this result. By using considerable forethought, the government has refrained from resorting to economic populism in an effort to boost short-term growth. In the absence of these institutions South Africa could be rendered vulnerable as it is plagued by high unemployment, widening inequality, poverty, AIDS related deaths and a rapid increase in the crime rate.

South Africa has undertaken many reforms - legislative, institutional, administrative, and otherwise - in order to create a climate conducive for the improvement of the quality of life of her inhabitants in accordance to the MDGs. Policy changes include (Millennium development goals: South Africa mid-term country report, 2007):

1. cash transfers in the forms of social assistance grants and social wage packages (which includes clinicbased free primary health care for all), compulsory education for all those aged seven to thirteen and, to those who qualify, subsidised housing, electricity, water, sanitation, refuse removal and transportation. The value of the social wage package was estimated at US\$13 billion in 2003,

2. the introduction of no-fee schools, which make it possible for over 40 per cent of learners in 14,000 schools to attend without paying fees. The provision of free transport to learners who live far away from school. In 2007, more than 200,000 learners benefited from this service,

3. the adoption of the Primary School Nutrition Programme, which provides one meal a day to primary school learners. In 2006, approximately six million learners benefited from the school nutrition programme, and

4. the implementation and monitoring of the Comprehensive Plan for HIV and AIDS as well as the Intersectoral Strategic Plan for HIV and AIDS for 2007 to 2011. These include the provision of public health facilities that provide voluntary counselling treatment, nutritional supplements to people living with HIV and AIDS, TB and other debilitating conditions and treating opportunistic infections.

Since September 2007, South Africa has had some success pertaining to the achievement of the MDGs. These include (i) an increase in the income of the poorest 10 and 20 per cent of the population; (ii) a reduction in the number of cases of severe malnutrition amongst children under 5 years of age from 88,971 to 30,082; (iii) a decline in HIV prevalence in women in the 20 to 24 year age group from 30.6 per cent to 28.0 per cent; and (iv) in terms of women's advancement in governance, South Africa's Parliament is now ranked $10^{\text {th }}$ out of 130 Parliaments worldwide (Millennium development goals: South Africa mid-term country report, 2007). Most of the reports about South Africa's progress towards the MDGs state that it is well on its way to meeting them.

Although these development improvements are certainly welcome, commendable and beneficial, concerns remain on whether the numerous policy changes have been too focused on achieving specific development goals and at a cost to improvements in general development. Areas of critical concern include (i) increases in income inequality; (ii) improvements in the incomes of the poorest 10 and 20 per cent of the population are not enough (the Poverty Head Count Index is estimated to be only 43.2 per cent); (iii) gender inequality in educational institutional attendance (for the 15 to 24 year old age group, the Gender Parity Index (GPI) for illiteracy values is less than one); (iv) no decreases (and in some instances) in HIV prevalence in the 30 to 40+ year age group; (v) no substantial 
decrease in the number of malaria cases since $1999^{5}$; (vi) access to improved sanitation facilities is only about 60 per cent for the general population and in excess of 30 per cent (as a percentage of urban population) for the slum population $^{6}$ (AEO, 2009). Many of these issues are associated with location and have clear spatial-patterns within South Africa.

\section{DEVELOPMENT MEASURES IN SOUTH AFRICA}

Sub-national development patterns for South Africa show spatial unevenness across a wide range of development indicators; Figures $1-4$ present 2006 values, where darker (lighter) shades illustrate lower (higher) values.

Figure 1 shows the sub-national pattern for primary education. The magisterial districts with the lowest amount of people in terms of primary education are located in the Provinces of Limpopo, Eastern Cape and the North West. This is to be expected as these Provinces have two major obstacles to overcome: first, the average learner-to-educator ratio is 30:1, and second, the educator standard is in question as literacy and numeracy achievements of the average $3^{\text {rd }}$ grader lags severely behind acceptable international standards; for instance, in Limpopo, Eastern Cape and the North West the percentage of $3^{\text {rd }}$ graders able to achieve the appropriate literacy and numeracy levels are 24 and 26, 35 and 36, 25 and 29 per cent, respectively (South African Development Indicators, 2010). What is perhaps more noticeable is that the districts with lower values are within major urban areas; these low values are in line with greater proportions of higher educational level attainment in urban areas. The realisation of the MDG concerned with achieving universal primary education is achievable but there are geographical areas of South Africa, which are primarily rural, that require substantially greater investments. Accessibility to primary education may be problematic in rural areas due to the home-school distance and low school density, and may further constrain the ability for South Africa to achieve this MDG.

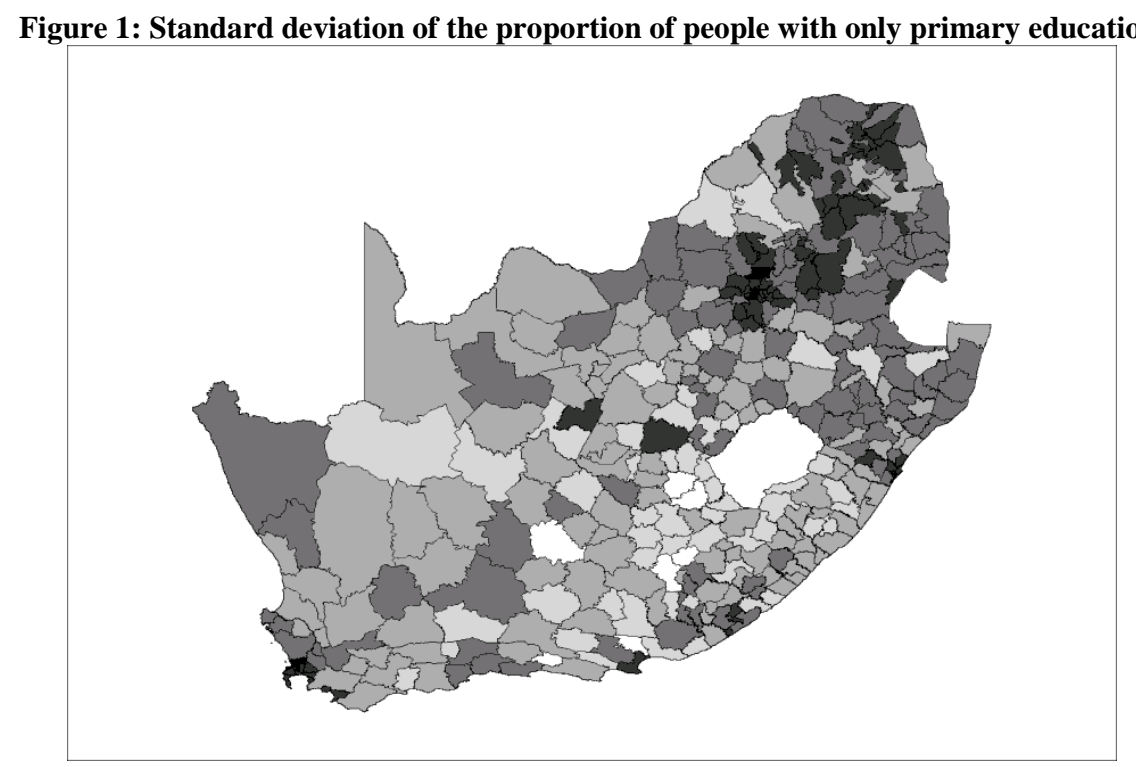

Figure 2 shows the sub-national pattern for human development index (HDI). The magisterial districts with the lowest HDI are located in KwaZulu-Natal, Eastern Cape and the North West Province. This is not surprising as

5 The fatality rate decreased by only 0.1 per cent year ending 2006 (Millennium development goals: South Africa mid-term country report, 2007).

6 The proportion of people living in slums is represented as the urban population living in households characterised by at least one of the following: (i) lack of access to improved sanitation, (ii) lack of access to improved water supply, (iii) overcrowding (3 or more persons per room) and (iv) dwellings made of non-durable materials (AEO, 2009). 
the literacy rates in these Provinces are below 70 per cent and the average income per capita is less than US\$ 2200 . The main geographical area of concern is primarily the rural Indian Ocean seaboard, away from urban greater Durban city-region.

Figure 2: Human Development Index

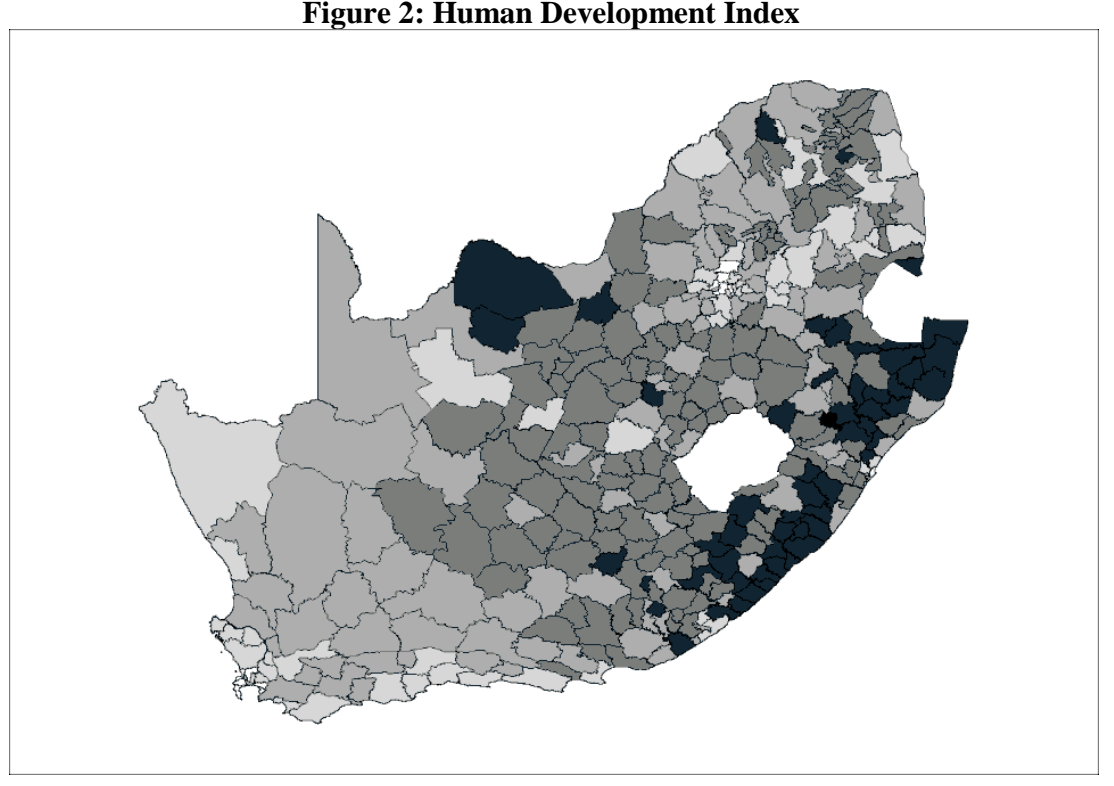

Figure 3 presents the sub-national pattern for the amount of people living on less than US\$2 a day. As can be seen high proportions can be found in the Eastern Cape, KwaZulu-Natal and Limpopo Provinces. In these three regions, a staggering 21-23 per cent of the population live on less than US\$2 a day. This should be expected as these Provinces are plagued with low education and low development. The first MDG is to halve extreme poverty and with such a large amount of people still living on less than US $\$ 2$ a day in mainly rural areas, this goal does not seem attainable for these regions unless migration to urban areas is strongly orchestrated.

Figure 3: Standard deviation of the percentage of people living on less than US\$2 a day

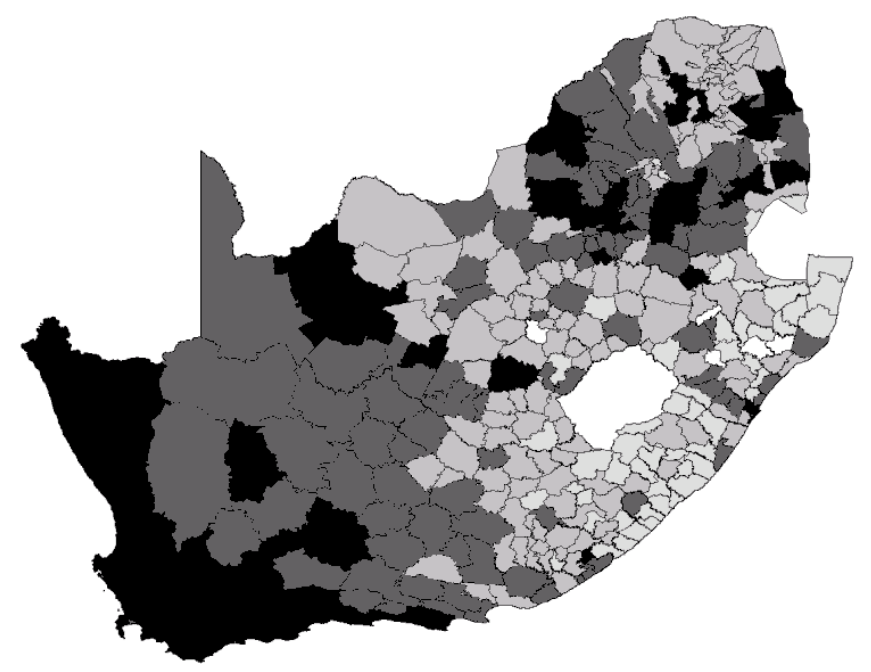


Figure 4 presents the sub-national pattern for HIV/AIDS. From the estimated 22.5 million people living with HIV/AIDS in Sub-Sahara Africa, an incredible 5.6 million (24.89 per cent) of them are located in South Africa. Of those positioned in South Africa, an excess of 2.9 million (53 per cent) are situated in only three Provinces; KwaZulu-Natal, Gauteng and the Eastern Cape. Preventing the spread of HIV/AIDS, which is the $6^{\text {th }}$ MDG, may not be currently feasible for these Provinces by 2015 as South Africa is still facing the world's largest HIV epidemic. According to Figure 4, and contrary to the previous three Figures, HIV does not have a clear urban/rural dimension but there does appear to be areas of the inland Western Cape that have exceptionally high incidence rates.

Figure 4: Standard deviation of the proportion of people living with HIV/AIDS

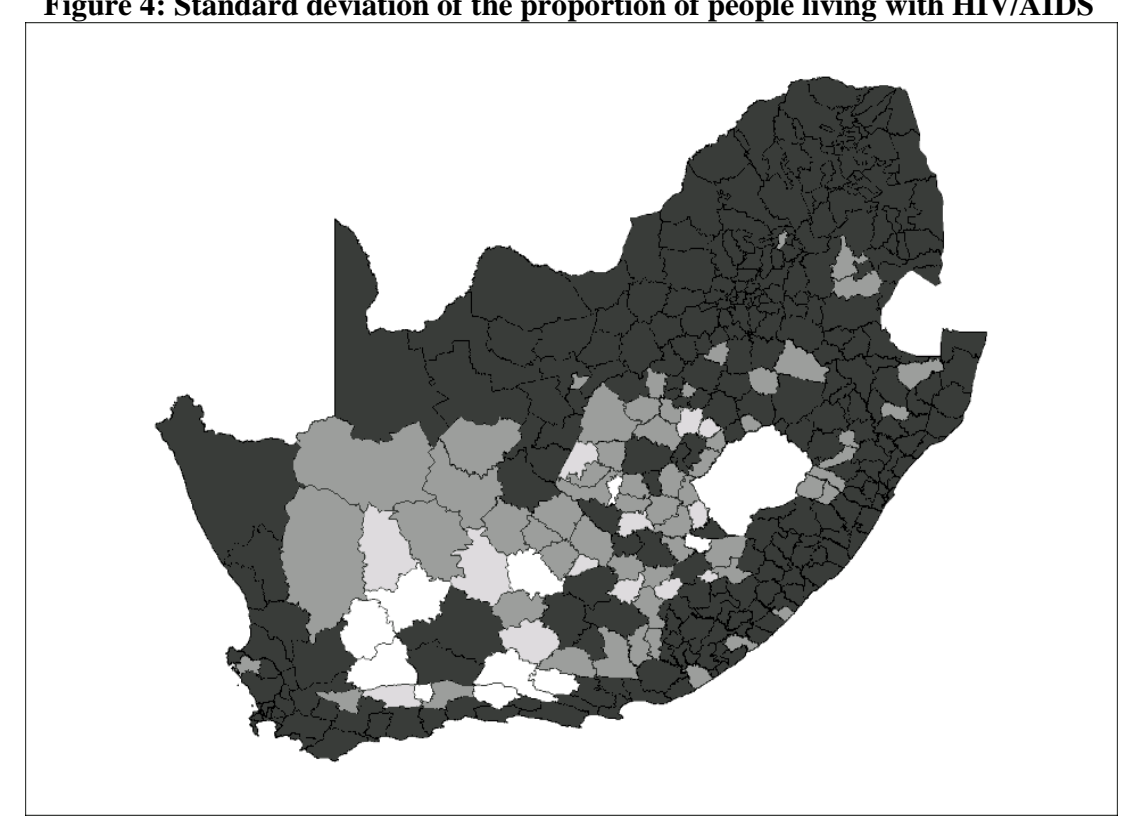

\section{DISCUSSION}

Inspection of Figures $1-4$ illustrates the wide variety of sub-national development levels that are observable for South Africa. The ability of individual countries to achieve MDGs will be dependent on the distance between current levels and the goals. On a cross-section of measures, as highlighted in the graphs above, the achievement of MDGs will be easier in some areas within a county than for others.

If resources, which are inherently limited, are allocated efficiently to achieve MDGs then they can be achieved at least cost through the improvement of measures that require the least amount of improvement. Scale and agglomeration economies mean that the achievement of parameter improvements will often be easiest in larger conurbations, such as city-regions or other areas where population density is higher and where the development indicators are better, and therefore further resource allocations will optimally be allocated to those areas.

However the risk involved with such resource allocations is that the benefits of these initiatives may be at a risk of greater development and vulnerability inequalities within countries. Further increases in development and vulnerability inequalities may stimulate faster rural-urban migration than is optimal and generate further socioeconomic problems, such as large pools of unemployment in city-regions that can lead to faster development of slums, a growing underworld culture and a ramping up of criminal activities which could stifle further entrepreneurial investments and initiatives that could be geared towards economic growth and development and indirectly to welfare improvements for all of society. 


\section{CONCLUSION}

This paper has discussed the idea that sub-national variations in different development and vulnerability measures mean that the achievement of the MDGs will be easier and cheaper if resources, that are inherently limited, are allocated to areas where smaller improvements in such indicators are required to achieve the goals; these areas are likely to be urban areas. It was illustrated that spatial disparities in socio-economic variables exist within a country and that these difference between various regions could hamper a country's overall achievement of the MDGs by 2015.

\section{AUTHOR INFORMATION}

Dr Stephanié Rossouw's research interests remain in, but are not limited to, the measurement of quality of life. She is actively investigating regional quality of life in New Zealand with a particular focus on entrepreneurial quality of life and whether it could be linked to the ease of doing business in a particular country. She is also investigating whether quality of life and distance interact to influence migration patterns between OECD countries. Recently, Stephanié has taken an interest in geographical economics, particularly how it relates to socio-economic indicators and the achievement of the United Nation's millennium development goals.

Dr Don Webber is an associate professor in the Department of Economics at Auckland University of Technology. His main area of research is regional economics, although he also actively researches topics in the economics of education and labour economics. Currently he is concentrating on the comparative economic performance of areas, such as regions, cities, countries, and the urban-rural divide. He is also working on 'Microeconomic foundations of spatial variations in labour productivity' and 'The role of structural change in productivity convergence'.

\section{REFERENCES}

1. African Economic Outlook. See Millennium development goals: progress report.

2. Atkins, J., Mazzi, S. and Easter, C. 2000. A commonwealth vulnerability index for developing countries: the position of small states. Economic Paper No. 40.

3. Bird, K and Prowse, M. 2008. Vulnerability, poverty and coping in Zimbabwe. WIDER Research Paper 2008/41. Helsinki: UNU-WIDER.

4. Birkmann, J. 2007. Assessing vulnerability before, during and after a disaster of natural origin: a case study of the tsunami in Sri Lanka and Indonesia. Paper presented at the UNU-WIDER Conference on Fragile States-Fragile Groups, Helsinki, 15-16 June.

5. Bocquier, P., Nordman, C.J. and Vescovo, A. 2010. Employment vulnerability and earnings in Urban West Africa. World Development, 38(9): 1297-1314.

6. Briguglio, L. 1995. Small island developing states and their economic vulnerabilities. World Development, 23(9): 1615-1632.

7. Briguglio, L. 2003. The vulnerability index and Small Island developing states: a review of conceptual and methodological issues. Paper prepared for the AIMS Regional Preparatory Meeting on the Ten Year Review of the Barbados Programme of Action, Praia, Cape Verde, 1-5 September.

8. Calvo, C. 2008. Vulnerability to multidimensional poverty: Peru, 1998-2002. World Development 36(6): 1011-1020.

9. Chakravarty, S. R. and Majumder, A. 2008. Millennium development goals: measuring progress towards their achievement. Journal of Human Development and capabilities, 9(1): 109-129.

10. Chaudhuri, S., Jyotsna, J. and Suryahadi, A. 2002. Assessing household vulnerability to poverty from cross-sectional data: a methodology and estimates from Indonesia. Discussion Paper Series 0102-52, Department of Economics, Columbia University.

11. Collas-Monsod, S., Monsod, T.C and Ducanes, M. 2004. Philippines' progress toward the millennium development goals: geographical and political correlates of subnational outcomes. Journal of Human Development and Capabilities, 5(1): 121-149.

12. Easter, C. 1998. Small states and development: a composite index of vulnerability. In Small States: Economic Review and Basic Statistics, Annual Series 4. (London: Commonwealth Secretariat) 
13. Fuentes, R. and Montes, A. 2004. Mexico and the Millennium development goals at the subnational level. Journal of Human Development and Capabilities, 5(1): 97-120.

14. Gaiha, R. and Imai, K. 2008. Measuring vulnerability and poverty: estimates for rural India. WIDER Research Paper 2008/40. Helsinki: UNU-WIDER.

15. Global report: UNAIDS report on global aids epidemic. 2010. United Nations programme on HIV/AIDS (UNAIDS). WHO Library Cataloguing-In-Publication Data, 2010.

16. Guillaumont, P. 2004. On the economic vulnerability of low income countries. In L. Briguglio and E. J. Kisanga (Eds) Economic Vulnerability and Resilience of Small States (Malta: Islands and Small States Institute of the University of Malta. London: Commonwealth Secretariat.)

17. Guillaumont, P. 2009. An Economic Vulnerability Index. Oxford Development Studies, 37(3): 193-228.

18. Hulme, D., Moore, K. and Shepherd, A. 2001. Chronic poverty: meanings and analytical frameworks, CPRC Working Paper no. 2. Manchester: Institute of Development Policy and Management.

19. Ivaschenko, O. and Mete, C. 2008. Asset-based poverty in rural Tajikistan. WIDER Research Paper 2008/26. Helsinki: UNU-WIDER.

20. Kanbur, R. and Venables, A. J. 2005. Rising spatial disparities and development. Policy Brief, 3. United Nations University, World Institute for Development Economics Research, Finland: Helsinki.

21. Kühl, J. J. 2003. Disaggregating household vulnerability - analyzing fluctuations in consumption using a simulation approach. Manuscript, Institute of Economics, University of Copenhagen.

22. Mansuri, G. and Healy, A. 2001. Vulnerability prediction in rural Pakistan. Washington D.C.: World Bank.

23. Marchante, A. J. and Ortega, B. 2006. Quality of life and convergence across Spanish regions, 1980-2001. Regional Studies, 40(5): 471-483.

24. McGillivray, M., Naudé, W. A. and Santos-Paulino, A. U. 2008. Achieving growth in the Pacific Islands: introduction. Pacific Economic Bulletin, 23(3): 97-101.

25. Millennium development goals: progress report. 2009. African Economic Outlook.

26. Millennium development goals: South Africa mid-term country report. 2007. The Presidency, Government of South Africa.

27. OECD. 2008. Economic assessment of South Africa. Report prepared by the Public Affairs and Communications Directorate. Policy brief, July.

28. South African Development Indicators. 2010. The Presidency: National Planning Commission, 2010. Retrieved 18 January 2010, from http://www.thepresidency.gov.za/MediaLib/Downloads/Home/Publications/NationalPlanningCommission4 /Development\%20Indicators2010.pdf

29. Turvey, R. 2007. Vulnerability assessment of developing countries: the case of small island developing states. Development Policy Review, 25(2): 243-264. 
NOTES 